\title{
Expression and secretion of staphylococcal nuclease in yeast: effects of amino-terminal sequences
}

\author{
OPHRY Pines* and Aliza LoNDON \\ Department of Molecular Biology, The Hebrew University-Hadassah Medical School, Jerusalem, Israel
}

(Received 18 June 1990; revised 20 November 1990; accepted 27 November 1990)

\begin{abstract}
Staphylococcus aureus nuclease A hybrid genes, encoding proteins OmpA-nuclease, lipo-nuclease and Pinnuclease, were cloned downstream of the yeast GAL10 inducible promoter. OmpA-nuclease and lipo-nuclease contain the mature staphylococcal nuclease sequence preceded by the Escherichia coli OmpA and lipoprotein signal sequences, respectively, whereas Pin-nuclease lacks a defined signal sequence at its amino terminus. We found that: (a) the nuclease gene products synthesized in yeast are active, but they do not affect cell growth; (b) OmpAnuclease and lipo-nuclease are partially processed and constitute approximately 1.0-1.5\% of the yeast cell protein; (c) OmpA and lipoprotein signal sequences function similarly in secretion, allowing $35-40 \%$ of the processed nuclease to be translocated into the yeast periplasm; and $(d)$ Pin-nuclease, which lacks hydrophobic sequences at its amino-terminus, is accumulated at a level tenfold lower than the hybrid proteins that do contain signal sequences. Nevertheless, $50 \%$ of the enzyme activity of Pin-nuclease in yeast is localized in the periplasmic space.
\end{abstract}

\section{Introduction}

Staphylococcus aureus nuclease A (also referred to as micrococcal nuclease) is a small (149 amino acids), extracellular phosphodiesterase that hydrolyses RNA and DNA to 3'-phosphomononucleotides. The protein lacks disulphide bonds and its activity can be assayed both qualitatively and quantitatively with ease (Anfinsen et al., 1971; Shortle, 1983). In addition, it has been the subject of numerous biochemical and biophysical studies including X-ray crystal analysis (Cotton et al., 1979). The results of these studies together with the pioneering studies of Taniuchi \& Anfinsen (1971) on the intramolecular interactions that are required for nuclease activity, mean that staphylococcal nuclease can serve as a useful marker for secretory processes. The staphylococcal nuclease gene has been cloned, sequenced and subjected to extensive genetic manipulation (Shortle, 1983; Shortle \& Lin, 1985). A hybrid gene encoding the Escherichia coli OmpA signal sequence fused to the mature portion of staphylococcal nuclease has been shown to be efficiently secreted and correctly processed in E. coli (Takahara et al., 1985). In contrast, a nuclease lacking the amino-terminal signal sequence is not secreted from $E$. coli and is lethal in the presence of high concentrations of $\mathrm{Ca}^{2+}$.

In order to allow a comparative analysis of eukaryotic and prokaryotic secretion systems, we have previously expressed a hybrid prokaryotic secretory protein gene in yeast (Pines et al., 1988a). The protein lipo- $\beta$-lactamase contains the major $E$. coli lipoprotein signal sequence plus nine amino acids attached to the mature portion of $\beta$-lactamase. We found that the processed lipo- $\beta$ lactamase accounted for $40 \%$ of the total hybrid protein. Processing of the lipoprotein signal peptide in yeast occurred at a unique site between cysteine 21 and serine 22 , one residue from the $E$. coli signal peptidase II processing site. The resulting mature lipo- $\beta$-lactamase was translocated across the cytoplasmic membrane into the yeast periplasm. These findings allowed us to construct and explore the effect of lipoprotein signal peptide mutants on secretion in yeast. We found that removal of the basic domain, or alteration of the cleavage site of the signal peptide, did not affect secretion of this heterologous protein in yeast. Removal of four hydrophobic amino acid residues from the hydrophobic domain did not affect secretion either; however, a significant stretch of hydrophobic amino acids remained intact in this case. A hydrophobic domain has been claimed to be the most important characteristic of the signal sequence that is essential for efficient secretion of (yeast) invertase in yeast (Kaiser et al., 1987; Ngsee et al., 1989).

The study presented here describes the expression in yeast of three staphylococcal nuclease derivatives with differing amino-terminal sequences. The distribution of the proteins and their activities in subcellular fractions of yeast is reported. 


\section{Methods}

Strains and growth conditions. The Saccharomyces cerevisiae strain DMM1-15A (leu 2 ura 3 ade 2 his5) has been described previously (Pines et al., 1988a). The growth medium (SD) used in all experiments contained $0.67 \%(w / v)$ nitrogen base without amino acids and $2 \%(w / v)$ of either glucose or galactose, and was supplemented with the appropriate amino acids. Cultures were grown to stationary phase (12$24 \mathrm{~h}$ ) in SD glucose medium at $30^{\circ} \mathrm{C}$. These cultures were then used to inoculate fresh SD media supplemented with the appropriate carbon source. E. coli strain JM109 was used for cloning using standard techniques as described by Maniatis et al. (1982).

Construction of staphylococcal nuclease expression vectors. Nuclease expression vectors were constructed from the yeast YEp51 plasmid (Broach et al., 1983) into which sequences encoding hybrid nuclease proteins were ligated (Fig. 1). The hybrid nuclease sequences were prepared from previously described plasmids encoding specific signal peptides and amino-terminal sequences which were fused to the sequence encoding the Staph. aureus nuclease A mature protein. The hybrid nuclease sequences presented in Fig. 1 were prepared as follows. (1) pDP-omp contains the XbaI-SalI fragment of plasmid pONF1, which encodes the OmpA signal sequence, ligated to the staphylococcal nuclease mature portion (Takahara et al., 1985). There are no linker or other sequences situated between the OmpA signal sequence and the staphylococcal nuclease mature sequence, since these were specifically removed on construction of pONFI (Takahara et al., 1985). (2) pDPlpp contains the $X b a \mathrm{I}-\mathrm{BamHI}$ fragment from PIN-IIIC3 (Masui et al., 1983), encoding the $E$. coli lipoprotein signal peptide, which we ligated to the BamHI-Sall fragment of PIN-III-OmpA3-\#98 encoding the staphylococcal nuclease mature portion (Takahara et al., 1985). (3) pDP-pin contains the $X b a I-B a m H I$ fragment from PIN-IIIA3 (Masui et al., 1983), encoding an amino terminus without a signal peptide, which we ligated to the BamHI-SalI fragment of PIN-III-OmpA3\#98 (Takahara et al., 1985).

For each fragment described above, the $\mathrm{XbaI}$ and SalI sites were changed to SalI and BamHI, respectively, allowing subsequent insertion of the fragment into the SalI and BamHI sites downstream of the GAL10 promoter in YEp51.

Cell labelling and immunoprecipitation. Sacch. cerevisiae DMM1-15A cells, containing the appropriate plasmid, were grown to a concentration of $4 \times 10^{7}$ cells $\mathrm{ml}^{-1}$ in SD galactose medium lacking methionine, and then labelled with $20 \mu \mathrm{Ci}(0.74 \mathrm{MBq})\left[{ }^{35} S\right]$ methionine $\mathrm{ml}^{-1}$ for $60 \mathrm{~min}$ at $30^{\circ} \mathrm{C}$. The labelled cells were collected by centrifugation and either broken with glass beads for total cell extracts or subjected to subcellular fractionation. Samples were immunoprecipitated with rabbit Staph. aureus nuclease A antiserum and formaldehyde-treated Staph aureus A Cowan cells (Kessler, 1975) and then analysed by SDSPAGE. A Zeineh soft laser scanning densitometer (model SL-TRFF; Biomed Instruments) was used to quantify autoradiograph bands.

Subcellular fractionation. Subcellular fractionation of cells was performed as previously described (Pines et al., 1988a). $\left[{ }^{35}\right.$ S $]$ Methionine-labelled yeast cells harbouring the appropriate plasmid were washed and resuspended to a concentration of $2 \times 10^{8}$ cells ml $^{-1}$ in $0.5 \mathrm{ml}$ buffer A (1 M-sorbitol; $50 \mathrm{~mm}$-Tris/ $\mathrm{HCl}, \mathrm{pH} 7.4 ; 2$ mM-dithiothreitol; $10 \mathrm{~mm}-\mathrm{MgCl}_{2}, 20 \mathrm{~mm}$-sodium azide; $0.5 \mathrm{~mm}$-PMSF). To this, $30 \mu \mathrm{l}$ of a $2 \mathrm{mg} \mathrm{ml}^{-1}$ stock solution of Zymolyase-20T (Seikagaku Kogyo) was added, and the suspension was incubated at $30^{\circ} \mathrm{C}$ for $30 \mathrm{~min}$ with gentle shaking. Formation of spheroplasts was monitored with a microscope. The spheroplasts were harvested in a bench centrifuge at 1000 r.p.m. for $5 \mathrm{~min}$ at room temperature (the supernatant constituted the periplasmic fraction) and resuspended in $0.5 \mathrm{ml}$ buffer $\mathrm{B}$ ( $50 \mathrm{~mm}$-Tris $/ \mathrm{HCl}, \mathrm{pH} 7.4 ; 3 \mathrm{~mm}$-EDTA; $0.5 \mathrm{~mm}$ PMSF). The spheroplasts were broken by glass beads and centrifuged
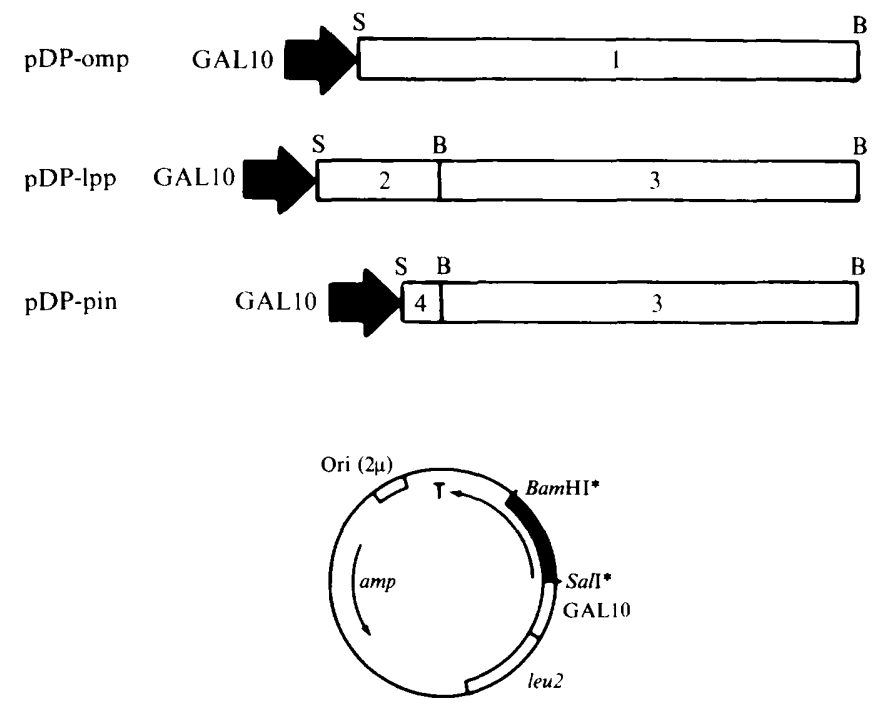

Fig. 1. Cloning of hybrid nuclease genes into YEp51. Fragments designated 1 (from pONF1), 2 (from PIN-IIIC3), 3 (from PIN-IIIOmpA3-\# 98) and 4 (from PIN-IIIA3) were cloned, in the order shown on the left, downstream of the GAL10 promoter in vector YEp51. The hybrid nuclease sequences (black box), cloned in vector YEp51, are shown on the left. $X b a I$ and $S a l I$ restriction sites in the source plasmids that were changed to $\mathrm{Sall}$ and $\mathrm{BamHI}$ sites, respectively are indicated by asterisks. S, SalI; B, BamHI; Ori, origin of replication from $2 \mu$ plasmid in yeast; $a m p$, ampicillin resistance marker; $\mathrm{T}$, termination site of GAL10-initiated transcription. Arrows show direction of transcription.

to recover a clear supernatant. Membrane and soluble spheroplast fractions were obtained by ultracentrifugation at $115000 \mathrm{~g}$ for $90 \mathrm{~min}$. Fractions were then subjected to immunoprecipitation and SDSPAGE as described above.

Enzyme activity. Indicator plates containing toluidine blue and calf thymus DNA were used for screening transformants, according to the method of Shortle (1983). For detection of activity on gels, samples of cellular fractions were incubated with $0.5 \mu \mathrm{g}$ closed circular plasmid DNA $(6.6 \mathrm{~kb})$ in $10 \mathrm{~mm}-\mathrm{CaCl}_{2}$ and $25 \mathrm{~mm}-\mathrm{Tris} / \mathrm{HCl}, \mathrm{pH} 8.7$. The total volume of the reaction mixture $(25 \mu \mathrm{l})$ was electrophoresed in a $0.7 \%$ agarose gel followed by staining with ethidium bromide. The spectrophotometric assay was performed according to the method of Cuatrecasas et al. (1967), using either calf thymus or salmon sperm DNA. One unit of enzyme activity is defined as the amount of enzyme causing a change of 1.0 absorbance unit $\mathrm{min}^{-1}$ at $260 \mathrm{~nm}$ (in a $1 \mathrm{~cm}$ cuvette).

Southern blot analysis. Yeast DNA was prepared as described by Sherman et al. (1983) and transferred to nitrocellulose, as described by Southern (1979). A $1.3 \mathrm{~kb}$ SalI-KpnI fragment of plasmid pHL $\Delta \mathrm{V}$ (Trecoet al., 1985), containing part of the leu 2 gene, was nick translated and used as a probe. Hybridization was performed in $3 \times$ SSC $(1 \times$ SSC is $0.15 \mathrm{M}-\mathrm{NaCl}, 0.015 \mathrm{M}$-sodium citrate), $3 \times$ Denhardt's solution (Denhardt, 1966) and $0.5 \%$ SDS at $65{ }^{\circ} \mathrm{C}$ for 12 to $16 \mathrm{~h}$. The nitrocellulose filter was then dried, and analysed by autoradiography. The plasmid copy number was estimated by the relative intensity of leu2 bands from plasmid and chromosomal origin.

Total yeast RNA isolation and RNA blot analysis. For preparation of total RNA from Sacch. cerevisiae, $200 \mathrm{ml}$ exponential-phase cultures $\left(2 \times 10^{7}\right.$ cells $\left.\mathrm{ml}^{-1}\right)$ were harvested and suspended in $2.5 \mathrm{ml}$ of LETS buffer $(0.1 \mathrm{M}-\mathrm{LiCl} ; 0.01 \mathrm{M}$-EDTA; $0.01 \mathrm{M}$-Tris/HCl, pH $7.4 ; 0.2 \%$ 
SDS). Cells were then broken with glass beads in $3 \mathrm{ml}$ phenol, equilibrated with LETS buffer. LETS buffer $(5 \mathrm{ml})$ was added, and the aqueous phase was extracted twice with $5 \mathrm{ml}$ phenol/chloroform/ isoamyl alcohol $(25: 25: 1$, by vol.) and once with chloroform. Finally, total yeast RNA was precipitated with $0 \cdot 1$ vol. $5 \mathrm{M}-\mathrm{LiCl}$ and 2 vols ethanol.

Nick translation of DNA probes and transfer of total RNA were performed as described by Maniatis et al. (1982). Filters were prehybridized at $42{ }^{\circ} \mathrm{C}$ for 2 to $4 \mathrm{~h}$ in $5 \times \mathrm{SSC}, 50 \%(\mathrm{v} / \mathrm{v})$ formamide, $5 \times$ Denhardt's solution, $0.5 \mathrm{mg}$ calf thymus DNA ml $\mathrm{m}^{-1}$ and $0.1 \% \mathrm{SDS}$. Hybridization was performed under the same conditions, except that the concentration of calf thymus DNA was reduced to $0.1 \mathrm{mg} \mathrm{ml}^{-1}$ and a denatured probe $\left(2 \times 10^{7}\right.$ to $3 \times 10^{7}$ c.p.m. $)$ was included. After hybridization for 15 to $20 \mathrm{~h}$, filters were washed with a solution containing $50 \%(\mathrm{v} / \mathrm{v})$ formamide and $5 \times \mathrm{SSC}$ at $42{ }^{\circ} \mathrm{C}$, followed by four further washes at $42{ }^{\circ} \mathrm{C}$ with a solution containing $5 \mathrm{~mm}-\mathrm{Tris} / \mathrm{HCl}$, $\mathrm{pH} 7 \cdot 0,25 \mathrm{~mm}-\mathrm{NaCl}, 1 \mathrm{~mm}-\mathrm{EDTA}$, and $0.1 \%$ SDS. The dried filters were then autoradiographed. The probes used for the Northern analysis included the PIN-III-OmpA3-\# 98 (Takahara et al., 1985), a BamHISal I $1.5 \mathrm{~kb}$ fragment and a $1 \mathrm{~kb}$ AvalI-HindIII fragment from the yeast actin gene $(\mathrm{Ng} \&$ Abelson, 1980) which was used as a control.

\section{Results}

\section{Construction of hybrid nuclease genes}

The expression of Staph. aureus nuclease A derivatives in yeast was devised as a means to examine the importance of the hydrophobic domain of the signal peptide in heterologous protein secretion, to compare secretion directed by two different bacterial signal peptides and to assess the effect of the mature portion of the secreted protein on its distribution in the yeast cell. In addition, it was our initial intention to develop a selection for yeast mutants that secrete heterologous proteins more efficiently based on the expected lethality of intracellular nuclease activity.

To examine the expression of Staph. aureus nuclease A derivatives in yeast, an inducible GAL10 expression system was used. Strong and sharp induction of the GAL10 promoter, in this system, occurs when cultures are grown with galactose as the carbon source. Cloned staphylococcal nuclease DNA sequences were situated between the yeast GAL10 promoter and transcription termination signals in the vector YEp51 (Broach et al., 1983). Three hybrid genes were constructed which encode nuclease proteins with differing amino-terminal protein sequences. The sources of the nuclease DNA sequences were plasmids pONF1 and PIN-III-ompA3\#98 (Takahara et al., 1985). Amino-terminus-encoding sequences were taken from pONF1 (Takahara et al., 1985), and from the PIN-IIIC3 and PIN-HIA3 vectors (Masui et al., 1983). A detailed description of the construction is provided in Methods.

Fig. 2 presents the partial amino acid sequences encoded by the constructed nuclease genes and shows the amino acid residues preceding the mature portion of nuclease A from Staph. aureus. In all three genes, the sequence of mature staphylococcal nuclease, starting with alanine, is identical to the unaltered mature sequence of the original protein. Lipo-nuclease contains the major E. coli lipoprotein signal peptide, plus nine amino acid residues of this protein, attached via a short linker sequence to the entire mature portion of the staphylococcal nuclease protein. This same aminoterminal sequence was previously used to direct secretion of $\beta$-lactamase in yeast (Pines et al., 1988a). OmpAnuclease encodes the signal peptide from the $E$. coli protein, OmpA, which is directly attached to the mature portion of staphylococcal nuclease. In this case, there are no linker or mature OmpA sequences situated between the OmpA signal peptide and the mature staphylococcal nuclease sequence. Pin-nuclease contains 14 amino acid residues preceding the staphylococcal nuclease mature portion. This amino-terminal sequence lacks what appears to be the most important feature of the signal peptide, namely the hydrophobic domain. In fact, this stretch of amino acids does not even contain two adjacent hydrophobic amino acid residues.

\section{Activity of staphylococcal nuclease in yeast cells}

The constructed hybrid nuclease expression vectors pDP-Ipp, pDP-omp and pDP-pin, encoding the projected proteins lipo-nuclease, OmpA-nuclease and Pin-nuclease, respectively, were used to transform the leucine-requiring yeast strain DMM1-15A. Since it was possible, and even expected (Barnes \& Rine, 1985; Pines et al., 1988b), that expression of a nuclease in yeast may be lethal, transformants were screened for inducible production of nuclease activity. Cell-free extracts were lpp-nuclease
MetLysAlaThrLysLeuValLeuglyAlaVali leLeuglySerThrLeuLeuAlaglyCysSer-
-SerAsnAlaLys IleAspArgGly I leProSerLeuAspProThrValTyrSer Ala

OmpA-nuclease
MetLysLysTrAlaIleAlaIleAlaValAlaLeuAlaglyPheAlaThrValAlaglnAla Ala

Pin-nuclease

MetLysGlyGlyIleP roSerLeuAspProThrValTyrSer $\longdiv { A l a }$
Fig. 2. Partial amino acid sequences of hybrid nuclease genes. Arrows indicate the positions of processing, in $E$. coli, of lipoprotein and $O m p A$, respectively. The boxed alanine indicates the first amino acid of the original mature Staph. aureus nuclease A protein. 
Table 1. Distribution of staphylococcal nuclease activity in yeast cells

Sacch. cerevisiae DMM1-15A cells, harbouring the appropriate plasmids, were induced in galactose medium, treated with Zymolyase and then subjected to subcellular fractionation. Nuclease activity was determined spectrophotometrically as described in Methods. Activity of control strains was negligible.

\begin{tabular}{lcccc}
\hline \hline & & \multicolumn{3}{c}{ Percentage in: } \\
\cline { 3 - 5 } \multicolumn{1}{c}{ Protein } & $\begin{array}{c}\text { Activity } \\
\text { (units ml }\end{array}{ }^{-1}$ ) & Periplasm & Cytoplasm & Membrane \\
\hline Pin-nuclease & 2.9 & 54.8 & 17.5 & 27.7 \\
Omp-nuclease & 58.3 & 34.3 & 26.9 & 38.8 \\
Lipo-nuclease & 64.1 & 34.8 & 29.6 & 35.6 \\
\hline \hline
\end{tabular}

* One unit of enzyme activity is defined as the amount of enzyme causing a change of 1.0 absorbance unit $\min ^{-1}$ at $260 \mathrm{~nm}$.

prepared from cultures of transformed strains that had been grown overnight in either galactose or glucose medium, and samples of these extracts were spotted on to toluidine blue nuclease-indicator plates. All the strains obtained by transformation with any one of the nuclease expression vectors described above, grown in galactose medium, exhibited nuclease activity. In contrast, nuclease activity was not detected when these same strains were grown in glucose media or when strains harbouring control plasmids without staphylococcal sequences were examined. Even though it was obvious that substantial amounts of nuclease activity were being produced in yeast cells (Table 1), growth, under a variety of conditions, of strains harbouring any one of the constructed nuclease expression vectors was essentially the same as that of parent or control strains (data not shown). In particular, this was true for cells induced in galactose medium containing high concentrations of $\mathrm{Ca}^{2+}$, which is required for staphylococcal nuclease activity (Cuatrecasas, 1970). Furthermore, the same results were obtained with cells treated with sublethal concentrations of the calcium ionophore A23187 or trifluoperazine which cause entry of extracellular $\mathrm{Ca}^{2+}$ into the cell (Eilam, 1984; Halachmi and Eilam, 1989).

Staphylococcal nuclease is a relatively small protein and the mature form in its original host, Staph. aureus, consists of 149 amino acid residues. To examine the distribution of nuclease derivatives in yeast, we initially employed a simple and very sensitive method in which a supercoiled circular plasmid was treated with subcellular fractions of yeast cultures and then electrophoresed in an agarose gel. This method was devised to detect if the protein reaches the periplasm and if it is released into the culture medium because of its small size. As shown in Fig. 3 (lanes 3, 6, 9, 12), no activity was detected in the culture medium of any of the nuclease expressing stains,

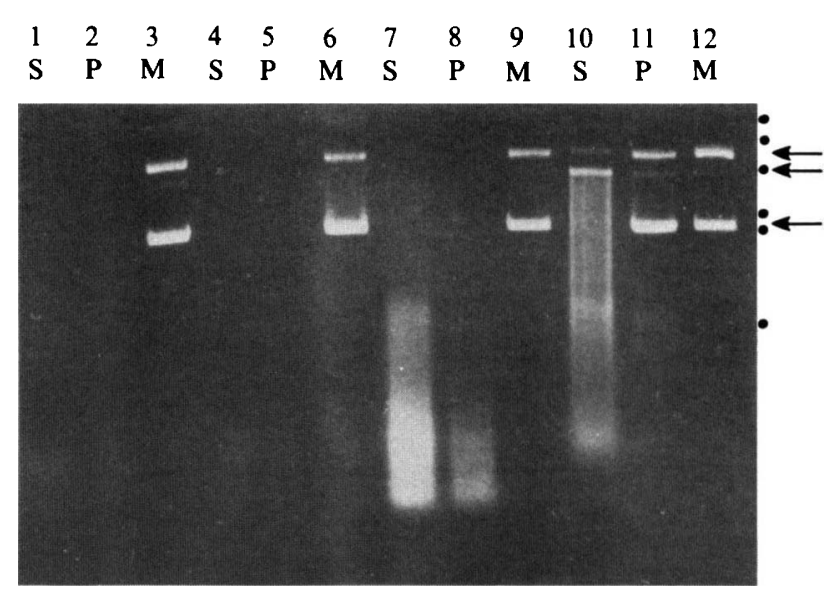

Fig. 3. Assay of nuclease activity in yeast. A closed circular supercoiled $6.6 \mathrm{~kb}$ plasmid $(0.5 \mu \mathrm{g})$ was treated with $1 \mu \mathrm{l}$ of periplasmic and spheroplast fractions, and $10 \mu \mathrm{l}$ of the culture-cell-free supernatant, for $30 \mathrm{~min}$ at $37^{\circ} \mathrm{C}$. The total volume of the assay mixture $(25 \mu \mathrm{l})$ was subjected to $0.7 \%$ agarose gel electrophoresis and stained with ethidium bromide. S, spheroplast, $\mathbf{P}$, periplasmic, and $\mathbf{M}$, culture supernatant fractions of cells expressing nuclease. Lanes: 1-3, liponuclease; 4-6, OmpA-nuclease; 7-9, Pin-nuclease; $10-12$, lipo- $\beta$ lactamase. Arrows show the position of supercoiled (bottom), linear (middle) and nicked (top) plasmid DNA. Dots show positions of fragments of $\lambda$ DNA digested with HindIII.

whereas substantial levels were detected in other subcellular fractions of strains harbouring the three staphylococcal nuclease plasmids as described in detail below.

From the analysis in Fig. 3 we can see already that the activity detected in strains harbouring pDP-omp and pDP-lpp is substantially higher than that in a strain harbouring pDP-pin (compare lanes 7 and 8 to lanes 1, 2, 4 and 5). A quantitative comparison between the nuclease activities in induced yeast cells harbouring nuclease expression vectors is shown in Table 1. Cell-free extracts were incubated with calf thymus DNA and the change in $A_{260}$ was followed. Strains induced with galactose harbouring either pDP-lpp or pDP-omp exhibited similar levels of nuclease activity. However, strains harbouring pDP-pin exhibited at least a tenfold lower nuclease activity than strains harbouring pDP-1pp and pDP-omp.

To examine the distribution of staphylococcal nuclease activity in yeast subcellular compartments, exponential-phase cells, harbouring plasmids pDP-lpp, pDPomp and pDP-pin, were induced in galactose medium and treated with Zymolyase 20-T to form spheroplasts which were collected and lysed, allowing fractionation of the cells into periplasmic and spheroplast fractions. Spheroplast fractions were further fractionated by ultracentrifugation into soluble cytoplasmic and membrane fractions. The results of the examination of nuclease 


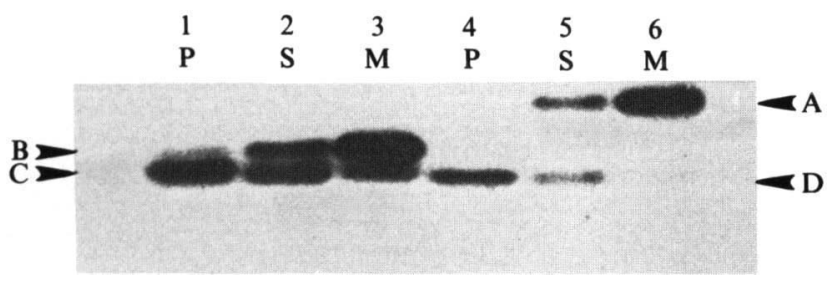

Fig. 4. Localization and processing of OmpA-nuclease and liponuclease. Exponential-phase yeast cells harbouring pDP-omp and pDP-lpp were induced in galactose medium and labelled for $60 \mathrm{~min}$ with $\left[{ }^{35} \mathrm{~S}\right]$ methionine. The labelled cells were fractionated into periplasm (P), soluble spheroplast (S) and membrane (M) subcellular fractions (as described in Methods). Extracts of cells expressing OmpA-nuclease (lanes 1,2,3) and lipo-nuclease (lanes 4, 5, 6) were immunoprecipitated with antiserum to staphylococcal nuclease and subjected to SDS-PAGE. Arrows show positions of: (A) lipo-nuclease precursor; (B) OmpA-nuclease precursor; (C) mature OmpA-nuclease; (D) mature lipo-nuclease. The position of commercially obtained staphylococcal nuclease A coincides with band $C\left(M_{\mathrm{r}} \sim 17000\right)$.

activity by the gel assay and, quantitatively, by the spectrophotometric assay are shown in Fig. 3 and Table 1 , respectively. No activity could be detected in the periplasm of a control yeast strain (harbouring pCOPI, a lipo- $\beta$-lactamase expression vector) and extremely low activity was associated with the spheroplast (Fig. 3, lanes $10,11)$. High nuclease activity was detected in both the periplasmic and spheroplast fractions of strains expressing OmpA-nuclease and lipo-nuclease. The distribution of activity in subcellular fractions in these strains was similar, with about $35 \%$ secreted into the periplasm, 27 $30 \%$ in the cytoplasm and $36-39 \%$ associated with membranes (Table 1). It was remarkable to find that, even though Pin-nuclease lacks a defined signal sequence and was expressed at a low level in yeast, more than $50 \%$ of the activity accumulated in the strain harbouring pDP-pin was localized to the periplasmic space. The rest of the nuclease activity was distributed between cytoplasmic and membrane fractions.

\section{Processing and secretion of OmpA-nuclease and lipo- nuclease}

Previous studies showed that, in E. coli, the lipoprotein signal sequence is processed by signal peptidase II at residue 20 . In yeast this same signal sequence, when attached to $\beta$-lactamase, is processed at residue 21 , one amino acid residue away from the processing site in the bacterial system (Ghrayeb \& Inouye, 1983; Pines et al., $1988 b$ ). The OmpA signal sequence is processed in E. coli by signal peptidase I at residue 21 (Movva et al., 1980). To examine the expression of our hybrid staphylococcal nuclease genes in yeast, exponential-phase cells, harbouring plasmids pDP-lpp, pDP-omp and pDP-pin, were induced in galactose medium and were labelled with $\left[{ }^{35}\right.$ S $]$ methionine. Spheroplasts were prepared and lysed as described above, allowing fractionation of the cells into periplasmic, cytoplasmic and total membrane fractions. In order to identify nuclease cross-reacting material, samples of each fraction were immunoprecipitated with staphylococcal nuclease antiserum. As shown in Fig. 4, two inducible protein species were detected by SDS-PAGE for both OmpA-nuclease and lipo-nuclease. These bands were absent from the analysis of the same strain grown in glucose medium or control strains harbouring plasmids that lack staphylococcal nuclease genes (data not shown). For OmpA-nuclease, the estimated sizes of these protein species coincided with the sizes of the precursor and mature forms of OmpA-nuclease, as expressed in E. coli. However, for lipo-nuclease the situation was different: although the precursor lipo-nuclease appeared to be similar for the bacterial and yeast systems, the mature form was clearly smaller in yeast and was estimated to be similar in size to the mature nuclease in Staph. aureus. Again, it is important to point out that the same lipoprotein signal sequence, when attached to $\beta$-lactamase, is processed in yeast at a site only one amino acid residue away from the processing site in E. coli. Quantification of the amounts of radioactivity in each of the bands by densitometric scanning of the autoradiograph in Fig. 4 showed that the level of processing of OmpA-nuclease and lipo-nuclease (43 and $35 \%$, respectively) is similar. Furthermore, similar levels of secretion of mature nuclease were observed; approximately $35-40 \%$ of the processed protein was secreted and only small amounts of the precursor could be detected in the periplasm.

\section{Expression of the Pin-nuclease-encoding gene}

The measurements of staphylococcal nuclease activity described above prompted the question as to why strains expressing Pin-nuclease accumulate a relatively low level of enzyme activity compared to strains expressing OmpA-nuclease and lipo-nuclease. When cultures harbouring pDP-omp, pDP-lpp and pDP-pin were induced, labelled with $\left[{ }^{35} \mathrm{~S}\right] \mathrm{methionine}$ and subjected to SDSPAGE, OmpA-nuclease and lipo-nuclease were readily detected in gel patterns of total cellular proteins, whereas Pin-nuclease was not detected.

To examine this question in more detail, Pin-nuclease expression was carefully followed and compared to OmpA-nuclease expression. We found that we were only able to identify the Pin-nuclease product in yeast extracts (Fig. 5, lane 4) following heavy labelling of cultures $\left[100 \mu \mathrm{Ci}(3.7 \mathrm{MBq}) \mathrm{ml}^{-1}\right]$ and immunoprecipitation with staphylococcal nuclease antiserum. A single product was found between the precursor $\left(M_{\mathrm{r}} \sim 18500\right)$ and processed $\left(M_{\mathrm{r}} \sim 17000\right)$ forms of OmpA-nuclease on 


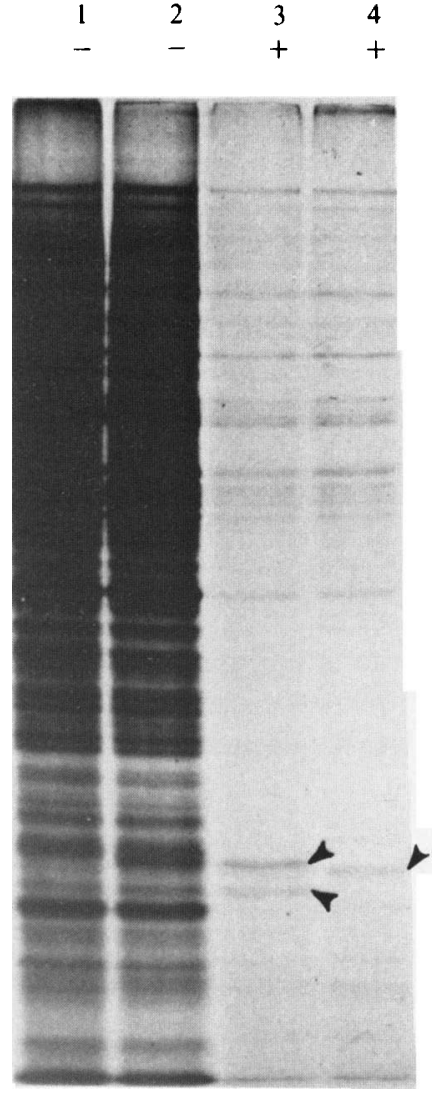

Fig. 5. Production of Pin-nuclease and OmpA-nuclease in yeast. Fxponential-phase cultures harbouring plasmids pDP-omp and pDPpin were induced in galactose medium and labelled for $2 \mathrm{~h}$ with $\left[{ }^{35}\right.$ S]methionine. Samples of extracts prepared from the labelled cells $(-)$ and samples immunoprecipitated with antiserum to staphylococcal nuclease $(+)$ were then analysed by SDS-PAGE. Extracts of cells expressing OmpA-nuclease (lanes 2,3) and Pin-nuclease (lanes 1, 4) are presented. Arrows show the positions of the precursor (top) and mature (bottom) forms of OmpA-nuclease and the Pin-nuclease product (middle). The estimated $M_{r}$ values of precursor and mature OmpAnuclease are 18500 and 17000 , respectively.

SDS-PAGE, as expected from the length of its sequence (Fig. 2). Densitometric scanning of the gel in Fig. 5 (lanes 3 and 4) indicated that the level of Pin-nuclease in yeast upon induction was about tenfold lower than the expression of OmpA-nuclease. OmpA-nuclease was estimated to constitute approximately $1.0-1.5 \%$ of total yeast cell protein under these conditions (lane 2 ). Thus, we may conclude that, in our experiments, differences in levels of nuclease activity in cell-free extracts correlate with the amount of the protein accumulated in yeast cells.

To examine the possible reasons for the low-level expression of Pin-nuclease we estimated (a) the copy number of pDP-pin and pDP-omp plasmids in yeast cells by Southern blot analysis (Fig. $6 a$ ) and (b) the level of Pin-nuclease and OmpA-nuclease mRNAs by Northern

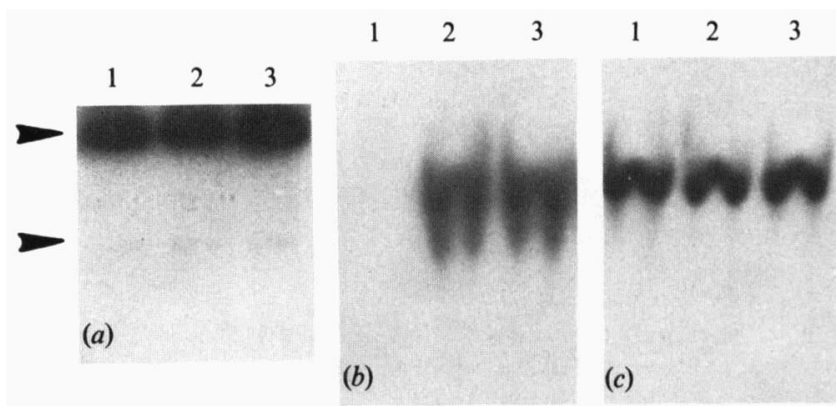

Fig. 6. Southern $(a)$ and Northern $(b, c)$ hybridization analysis of DNA and RNA from Sacch. cerevisiae strains. (a) Total cellular DNA from cells harbouring the appropriate plasmids was cleaved with Sall and $B a m H I$. The DNA was then subjected to agarose gel electrophoresis, transferred to nitrocellulose and probed with a $1.3 \mathrm{~kb}$ Sal I-KpnI fragment (from plasmid pHL $\Delta \mathrm{V}$ ) containing part of the leu 2 gene (Treco et al., 1985). Lanes 1,2 and 3 contain DNA from yeast cells harbouring YEp51, pDP-pin and pDP-omp, respectively. Arrows show the position of leu2 bands from chromosomal (top) and plasmid (bottom) origins. (b) Total cellular RNA from Sacch. cerevisiae cultures grown in galactose medium were subjected to $1 \%$ denaturing vertical agarose gel electrophoresis. RNA was transferred to nitrocellulose and probed with a $1.5 \mathrm{~kb}$ Bam HI-SalI fragment (from plasmid pINIIIOmpA3-\#98) which contains part of the staphylococcal nuclease gene (Takahara et al., 1985). Lanes 1,2 and 3 contain RNA from yeast cells harbouring YEp51, pDP-pin and pDP-omp, respectively. (c) Total yeast RNA was transferred to nitrocellulose as in $(b)$ and was probed with a $1 \mathrm{~kb}$ AcalI-HindIII fragment from the yeast actin gene $(\mathrm{Ng} \&$ Abelson, 1980). Gel order as in (b).

blot analysis (Fig. $6 b$ and $6 c$ ). We found the plasmid copy number for both pDP-pin and pDP-omp to be 30 35 copies per cell, as estimated by the relative intensity of leu 2 bands from plasmid and chromosomal origin (Fig. $6 a$, lanes 2 and 3). The level of staphylococcal nucleaseencoding mRNA (Fig. $6 b$, lanes 2 and 3 ) was similar for cells harbouring either pDP-pin or pDP-omp expression vectors. The level of actin mRNA was the same for the nuclease-expressing strains as for the control strain harbouring YEp5I (Fig. 6c), showing that the RNA was extracted from equivalent amounts of cells.

\section{Discussion}

Expression of Staph. aureus nuclease A in yeast revealed two aspects of heterologous secretion in this organism: (a) a significant portion of the processed protein is localized in the yeast periplasm and $(b)$ only a part of the hybrid nuclease gene products are processed and secreted. We have previously found a similar pattern of expression with another prokaryotic hybrid protein, lipo$\beta$-lactamase (Pines et al., 1988a). In addition, overexpression of certain heterologous eukaryotic proteins in yeast results in partial secretion (e.g. Smith et al., 1985). Thus, it appears that the information for secretion, in 
yeast, exists within the sequence of the nuclease and lipo$\beta$-lactamase prokaryotic hybrid proteins but is used inefficiently.

Where is the information that allows these prokaryotic proteins to be secreted? The amino-terminal signal peptide obviously contains information important for directing the protein into the eukaryotic endoplasmic reticulum and bacterial periplasm (Randall \& Hardy, 1989). In fact, we have shown that Pin-nuclease, which lacks a defined signal sequence, is synthesized at a level tenfold lower than the nuclease derivatives with intact signal sequences, and the total amount of Pin-nuclease which reaches the periplasm is relatively low. In contrast, both OmpA-nuclease and lipo-nuclease, which contain intact signal sequences from prokaryotic proteins, are synthesized at high levels $(1.0-1.5 \%$ of total yeast cell protein) and a significant amount of their processed products is secreted into the yeast periplasm. We have previously shown that elimination of the basic domain and alteration of the cleavage domain of the prokaryotic lipo- $\beta$-lactamase signal peptide does not affect secretion of that protein in yeast, even though the secretion of the same mutant proteins in $E$. coli is defective (Pines et al., 1988a). Whereas with lipo- $\beta$ lactamase, short deletions and substitutions of amino acid residues from the hydrophobic domain are tolerated, we have shown here that complete elimination of the staphylococcal nuclease hydrophobic domain strongly reduces the amount of nuclease accumulated in the yeast cell and periplasm, and no processing event is detected. Thus, it appears that the hydrophobic domain of the signal peptide is crucial for efficient secretion of these heterologous proteins in yeast. These results obtained with a heterologous protein are similar to observations of the secretion of the homologous yeast invertase, containing defective signal sequences (Kaiser et al., 1987; Ngsee et al., 1989: Preuss \& Botstein, 1989). Expression of invertase derivatives with signals lacking a hydrophobic domain at the amino-terminus results in a reduction in the synthesis of protein and in the amount secreted into the periplasm (Kaiser et al., 1987; Preuss \& Botstein, 1989). For invertase and staphylococcal nuclease, in yeast, it is possible that certain signal peptide alterations cause defects in both synthesis and secretion without affecting expression at the mRNA level. One way to explain this is to suggest an effect of the secretory apparatus on the translation of proteins that interact with it: a phenomenon that has been described in higher eukaryotes (Walter \& Blobel, 1981). This would correlate well with the fact that, in prokaryotes, various mutations in signal peptides affect synthesis and secretion coincidentally (2.9, Pollit et al., 1986). An alternative explanation for our results is that the altered signal peptide of Pin-nuclease leads to the production of a less stable product. Ngsee et al. (1989) have suggested that this is also the case for certain signal peptide mutants of invertase in yeast. Although we did not observe additional low- $M_{\mathrm{r}}$ Pin-nuclease bands, as Nysee et al. (1989) did with invertase, the possibility of Pin-nuclease instability cannot be ruled out.

The mature portion of the nuclease hybrid proteins contains information which is important for secretion in yeast, as indicated by the following observations. (a) The level of processing and secretion of lipo- $\beta$-lactamase and lipo-nuclease is quantitatively different, although they have an identical signal peptide and amino-terminus; lipo- $\beta$-lactamase in comparison to lipo-nuclease is processed more efficiently $(40 \%$ versus $20 \%)$ and the mature form is secreted more efficiently $(75 \%$ versus $40 \%$ ). (b) The site of signal peptide cleavage of liponuclease and lipo- $\beta$-lactamase is different even though, as described above, the amino-terminus of both proteins is identical. Lipo-nuclease is estimated to be processed at, or close to the first alanine of mature nuclease as expressed in Staph. aureus (Figs 2 and 4), whereas we have previously shown that lipo- $\beta$-lactamase is cleaved 19 amino acid residues upstream (Pines et al., 1988a). (c) Pin-nuclease, which lacks a defined signal sequence and is accumulated at low levels, is nevertheless secreted in yeast, indicating that the mature protein sequence can direct secretion.

The fact that high expression of nuclease in yeast cells is not lethal was surprising since active nuclease could be detected in both soluble and membrane fractions of yeast cells. The expression of the E. coli DNA restriction enzyme $E c o$ RI and the $E$. coli double-stranded-specific ribonuclease III (RNAase III) have been previously reported to be lethal in yeast (Barnes \& Rine, 1985; Pines et al., 1988b). Expression of RNAase III, for example, caused a $10^{4}$ - to $10^{5}$-fold reduction in yeast cell viability $3 \mathrm{~h}$ after induction of the gene encoding its activity. Staph. aureus nuclease A has potent DNAase and RNAase activity and can readily digest double- and single-stranded yeast DNA and RNA in vitro (data not shown). Furthermore, expression of staphylococcal nuclease activity in the E. coli cytoplasm has been shown to be lethal (Takahara et al., 1985). We suggest two possible explanations for this result. (a) The nuclease is inactive in vivo. For instance, staphylococcal nuclease specifically requires $\mathrm{Ca}^{2+}$ ions for its activity and, since Sacch. cerevisiae maintains a low concentration of these ions in its cytosol (Halachmi \& Eilam, 1989), the enzyme may not display activity in the cell. (b) Affinity of the nuclease for the secretory apparatus may render it unable to interact with potential substrates in the cell. This would also suggest that soluble nuclease within the cell is associated with components of the secretory pathway of yeast. 
The results of this study suggest that the lower eukaryote Sacch. cerevisiae can decipher prokaryotic secretory information within the signal peptide and mature portion of staphylococcal nuclease. Whereas the general structure of the signal peptide has been conserved during evolution (basic, hydrophobic and cleavage domains), only the hydrophobic domain can be shown by mutational and deletion analysis to be crucial for secretion in yeast. In this respect, the interaction of the signal sequence with important secretory information within the mature protein sequence has still to be investigated.

This work was supported by the Leszczynski Foundation.

\section{References}

Anfinsen, C. B., Cuatrecasas, P. \& Taniuchi, H. (1971). Staphylococcal nuclease, chemical properties and catalysis. In The Enzymes, vol. 4, pp. 177-204. Edited by P. Boyer. New York: Academic Press.

BARNES, G. \& RINE, J. (1985). Regulated expression of endonuclease EcoRI in Saccharomyces cerevisiae: nuclear entry and biological consequences. Proceedings of the National Academy of Sciences of the United States of America 82, 1354-1358.

BROACH, J., LI, Y., WU, L. C. \& JAYARAM, M. (1983). Vectors for highlevel inducible expression of cloned genes in yeast. In Experimental Manipulation of Gene Expression, pp. 83-117. Edited by M. Inouye. New York: Academic Press.

CotTon, F. A., HAzEN, E. E. JR, \& LEGG, M. J. (1979). Staphylococcal nuclease; proposed mechanism of action based on structure of enzyme-thymidine $3^{\prime}, 5^{\prime}$-bisphosphate-calcium ion complex at $1.5 \AA$ resolution. Proceedings of the National Academy of Sciences of the United States of America 76, 2551-2555.

CuAtreCasas, P. (1970). Topography of the active site of staphylococcal nuclease. Journal of Biological Chemistry 245, 574-584.

Cuatrecasas, P., Fuchs, S. \& Anfinsen, C. B. (1967). Catalytic properties and specificity of the extracellular nuclease of Staphylococcus aureus. Journal of Biological Chemistry 242, 1541-1547.

DENHARDT, D. T. (1966). A membrane-filter technique for the detection of complementary DNA. Biochemical and Biophysical Research Communications 23, 641-646.

EILAM, Y. (1984). Effects of phenothiazines on inhibition of plasma membrane ATPase and hyperpolarization of cell membranes in the yeast Saccharomyces cerevisiae. Biochimica et Biophysica Acta 769, 601-610.

GHRAYEB, J. \& INOUYE, M. (1983). Nine amino acid residues at the $\mathrm{NH}_{2}$-terminal of lipoprotein are sufficient for its modification, processing, and localization in the outer membrane of E. coli. Journal of Biological Chemistry 259, 463-467.

Halachmi, D. \& Eilam, Y. (1989). Cytosolic and vacuolar $\mathrm{Ca}^{2+}$ concentrations in yeast cells measured with the $\mathrm{Ca}^{2+}$-sensitive fluorescence dye indo-1. FEBS Letters 256, 55-61.

Kaiser, C. A., Preuss, D., Grisafi, P. \& Botstein, D. (1987). Many random sequences functionally replace the secretion signal sequence of yeast invertase. Science 235, 312-317.
KESSLER, S. W. (1975). Rapid isolation of antigens from cells with a staphylococcal protein A-antibody immunoabsorbent: parameters of the interaction of antibody-antigen complexes with protein $\mathrm{A}$. Journal of Immunology 115, 1617-1624.

Maniatis, T., Fritsch, E. F. \& Sambrook, J. (1982). Molecular Cloning: a Laboratory Manual. Cold Spring Harbor, NY: Cold Spring Harbor Laboratory.

Masui, Y., Coleman, J. \& InOuYe, M. (1983). Multipurpose expression cloning vehicles in Escherichia coli. In Experimental Manipulation of Gene Expression, pp. 15-32. Edited by M. Inouye. New York: Academic Press.

Movva, N. R., NaKamura, K. \& InOUYe, M. (1980). Gene structure of the OmpA protein, a major surface protein of $E$. coli required for cell-cell interaction. Journal of Molecular Biology 143, 317-328.

NG, R. \& ABELSON, J. (1980). Isolation and sequence of the gene for actin in Saccharomyces cerevisiae. Proceedings of the National Academy of Sciences of the United States of America 77, 3912-3916.

Ngsee, J. K., Hansen, W., Walter, P. \& Smith, M. (1989). Cassette mutagenic analysis of the yeast invertase signal peptide: effects on protein translocation. Molecular and Cellular Biology 9, 3400-3410.

Pines, O., Lunn, C. A. \& InOuYe, M. (1988a). Defective Escherichia Coli signal peptides function in yeast. Molecular Microbiology 2, 209217.

Pines, O., Yoon, H. J. \& INOuYe, M. (1988b). Expression of doublestranded-RNA-specific RNase III of Escherichia coli is lethal to Saccharomyces cerevisiae. Journal of Bacteriology 170, 2989-2993.

Pollit, S., InOuYe, S. \& INOUYE, M. (1986). Structure-function relationships of the signal sequence of $E$. coli outer membranelipoprotein. Microbiology 1986, 238-241.

Preuss, D. \& Botstein, D. (1989). Intragenic revertants of yeast invertase variants with secretion defective leader sequences. Molecular and Cellular Biology 9, 1452-1464.

Randall, L. L. \& Hardy, S. J. S. (1989). Unity in function in the absence of consensus in sequence: role of leader peptides in export. Science 243, 1156-1159.

Sherman, F., Fink, G. R. \& Hicks, J. B. (1983). Isolation of yeast nuclear and mitochondrial DNA. In Methods in Yeast Genetics, pp. 77-80. Cold Spring Harbor, NY: Cold Spring Harbor Laboratory.

SHORTLE, D. (1983). A genetic system for analysis of staphylococcal nuclease. Gene 22, 181-183.

SHORTLE, D. \& LiN, B. (1985). Genetic analysis of staphylococcal nuclease: identification of three intragenic 'global' suppresors of nuclease-virus mutations. Genetics 110, 539-545.

SMith, R. A., Duncan, M. J. \& MoIR, D. T. (1985). Heterologous protein secretion from yeast. Science 229, 1219-1224.

Southern, E. M. (1979). Gel electrophoresis of restriction fragments. Methods in Enzymology 68, 152-176.

Takahara, M., Hibler, D. W., Barr, P. J., Gerlt, J. A. \& InOUye, M. (1985). The ompA signal peptide directed secretion of nuclease A by Escherichia coli. Journal of Biological Chemistry 260, 2670-2674.

TANiUCHI, H. \& ANFINSEN, C. B. (197†). Simultaneous formation of two alternative enzymatically active structures by complementation of two overlapping fragments of staphylococcal nuclease. Journal of Biological Chemistry 246, 2291-2301.

TreCo, D., Thomas, B. \& ARnheim, N. (1985). Recombination hot spot in the human $\beta$-globin gene cluster : meiotic recombination of human DNA fragments in Saccharomyces cerevisiae. Molecular and Cellular Biology 5, 2029-2038.

W ALTER, P. \& Blobel, G. (1981). Translocation of proteins across the endoplasmic reticulum III : signal recognition protein (SRP) causes signal sequence-dependent and site specific arrest of chain elongation that is released by microsomal membranes. Journal of Cell Biology 91, 557-561. 